\title{
Investigation and Research on the Integration of Ideological and Political Education into Higher Mathematics Teaching
}

Lifeng Guo, Shuguo Wang

Tarim University, Alar 843300, Xinjiang, China.

Project: Ideological and Political Demonstration Team Project of Tarim University Advanced Mathematics Course (2201029006); Higher Education Research Program of Tarim University (TDGJYB2024).

Abstract: In order to study the problems existing in higher mathematics teaching under the background of "curriculum ideology and politics", through a questionnaire survey of college students to investigate and analyze the teaching situation of the integration of "curriculum ideology and politics" into higher mathematics courses, 114 valid questionnaires were collected and used. Comprehensive analysis and interactive analysis are carried out in-depth analysis, and it is concluded that it is better to adopt a diversified teaching method and combine advanced mathematics knowledge cases to intersperse the "curriculum ideological and political" teaching method. The "curriculum ideological and political" elements should pay attention to the integration of mathematical culture and mathematics grandmaster. Finally, some suggestions on how to integrate "curriculum ideology and politics" into higher mathematics courses are put forward.

Keywords: Curriculum Ideology; Questionnaire Survey; Teaching Situation

\section{Introduction}

Advanced mathematics is the foundation of modern mathematics. It is a compulsory course for students majoring in engineering, science, agriculture, and economics and management. It is also the most widely used course in modern science and technology, economics and management, and humanities. Therefore, it is very important to learn this course well for the future development of students. At present, domestic colleges and universities have successively carried out a series of "curriculum ideological and political" construction projects, closely focusing on the fundamental task of establishing morality, integrating ideological and political education into each course, integrating core socialist values into the whole process of education and teaching, and cultivating morality. They are socialist builder and successor of the all-round development of intellectual, physical, artistic and labor. This thesis relies on the advanced mathematics "curriculum ideological and political" demonstration team project, through the questionnaire survey of college students to investigate and analyze the teaching situation of the "curriculum ideological and political" integrated into the advanced mathematics curriculum, and use comprehensive analysis and interactive analysis to conduct in-depth analysis. Put forward some suggestions and opinions on how to integrate "ideological and political" into higher mathematics courses.

\section{Data source}

This project conducted a questionnaire survey on the students of Tarim University. A total of 120 questionnaires were distributed and 114 valid questionnaires were received. The subjects of the questionnaire survey covered students of advanced mathematics $\mathrm{A}, \mathrm{B}$, and $\mathrm{C}$.

Copyright $(2020$ Lifeng Guo et al.

doi: 10.18686/ahe.v4i10.2887

This is an open-access article distributed under the terms of the Creative Commons Attribution Non-Commercial License (http://creativecommons. org/licenses/by-nc/4.0/), which permits unrestricted non-commercial use, distribution, and reproduction in any medium, provided the original work is properly cited. 


\section{Questionnaire analysis of the integration of "curriculum ideology and politics" into the higher mathematics teaching process}

From the analysis of the questionnaire survey results, more than $70 \%$ of students believe that in addition to teaching knowledge in class, advanced mathematics teachers also pay attention to teaching how to behave. Advanced mathematics teachers can teach by word and deeds, which is a role model for students to learn. At the same time, advanced mathematics teachers spread to us Outlook on life and values consistent with socialist core values. More than $96 \%$ of students think it is necessary to integrate "curriculum ideology" into university courses, and 64\% of them think it is very necessary.

Four options are set in "Think the most appealing content of ideological and political courses in advanced mathematics": history of mathematics, mathematics masters, contemporary models, and mathematics culture. 43.9\% of people think mathematics culture is the most attractive thing in advanced mathematics. Students have a relatively high interest in mathematics culture. Therefore, in future teaching, teachers can try to integrate more mathematics culture into higher mathematics, and tell students more about cultural knowledge in mathematics to increase their interest in learning. Only $12.3 \%$ of people are interested in contemporary models. In future lectures, we should strengthen the introduction of students' contemporary models, especially those related to higher mathematics, so that contemporary models can be more attractive to students and improve students' sense of responsibility and patriotism.

Four options are set in "I think it is better to adopt a method to penetrate the ideological and political content in advanced mathematics courses": "Before starting the class, first talk about ideological and political and then advanced mathematics courses", "Combine advanced mathematics knowledge cases to intersperse ideological and political ", "Before the lecture is over, sum up knowledge and talk about ideological politics", "It doesn't matter". From the analysis results, 64\% of people think that the teaching method of "course ideological and political" should be interspersed with advanced mathematics knowledge cases before starting the class. It is good. Therefore, in the future teaching, you can try to put the content of "curriculum ideology and politics" into the citations and knowledge points, combine the specific content of higher mathematics with "curriculum ideology and politics", and give interspersed explanations, which students prefer. $31.6 \%$ of the people think that it is better to talk about "curriculum ideology and politics" and then the advanced mathematics course before starting the class. Before the end of the lecture, summarizing knowledge, ideological and political or indifferent accounted for less, and this method can be avoided in future teaching.

In the analysis of the question of "What are the suggestions for the introduction of curriculum ideology and politics in advanced mathematics", $58.8 \%$ of the students thought that the diversification of forms helped to integrate "curriculum ideology and politics" into the advanced mathematics curriculum. 17.5\% of people think that more interaction will help integrate "curriculum ideology" into higher mathematics courses. Therefore, in future teaching, teachers can try to diversify the forms, integrating the history of mathematics, ancient mathematics scientists, modern mathematics scientists, contemporary models, mathematics culture, socialist core values, Xinjiang spirit, and Populus Euphratica Spirit into the higher mathematics teaching process. More interactive activities with students will encourage students to learn advanced mathematics courses better and make mathematics courses less boring.

The results of the questionnaire survey showed that $96 \%$ of the students thought that the school paid more attention to curriculum ideological and political work, but different "curriculum ideological and political" content and different teaching methods affected students' understanding of the importance of the school. Taking "What do you think is most appealing to you in the ideological and political content of the advanced mathematics class?" and "Which way do you think it is better to use the ideological and political content in the advanced mathematics class?" as independent variables, "How do you think the school views curriculum ideological and political work?" As a dependent variable, interactive analysis shows that the "curriculum ideological and political" elements of the history of mathematics and contemporary models are incorporated into the courses of higher mathematics. No matter which way you teach, students generally not recognized, thinking that the school did not attach importance to "curriculum ideological and political" work. Therefore, in the teaching process, we should still pay attention to the integration of mathematics culture and mathematics masters, train students to inherit the excellent traditional Chinese culture, and promote the national spirit with patriotism as the core.

\section{Conclusion}

\subsection{Teachers should teach by precepts and deeds, and teach students how to behave}

Teachers should lead by example, not just preaching and solving problems, but more importantly, how to educate people. 
Through their own life experience and personal charm, they must be rigorous in teaching, be kind in their work, and improve their personal cultivation. Work attitude, enthusiasm, dedication, tolerance and other aspects to infect students and help them establish a correct outlook on life and values.

\subsection{Exploring the elements of "curriculum ideological and political", focusing on the integration of mathematics masters and mathematics culture}

In the teaching process, we must be good at digging out teaching cases that have a good effect on higher mathematics "curriculum ideological and political" education and good response from students, and form typical cases of "curriculum ideological and political" with strong reference and high promotion value to provide reference for improving the effect of curriculum education draw on. It is necessary to focus on the integration of some mathematical thoughts of ancient Chinese scientists with some concepts and ideas of advanced mathematics, and the integration of mathematical culture in traditional Chinese culture with some concepts and ideas in advanced mathematics to cultivate students' sense of responsibility and patriotism spirit. The integration points of "curriculum ideological and political" elements are formed into a system and written into the syllabus.

\subsection{Combining the knowledge points of advanced mathematics courses, interspersedly teaching the content of "curriculum ideological and political"}

Integrate "curriculum ideology and politics" into advanced mathematics courses. You should not regard advanced mathematics and "curriculum ideology and politics" as two skins. In the process of teaching, you must pay attention to combining the ideas, knowledge points, examples, etc. of advanced mathematics with the "curriculum". Combining ideological and political elements, integrating different ideological and political elements in different places, interspersing the content of "curriculum ideological and political" into the advanced mathematics curriculum, so that students are interested in advanced mathematics, not appearing boring, and continuously improving students' active learning ability.

\subsection{The integration of advanced mathematics into "curriculum ideology and politics" should pay attention to the diversification of forms}

Incorporate "curriculum ideological and political" into higher mathematics courses, and pay attention to the diversification of "curriculum ideological and political" elements in the teaching process. In the teaching process, teachers can try to diversify forms, not only to integrate the history of mathematics, ancient mathematics scientists, modern mathematics scientists, mathematics culture, etc., but also to integrate the core values of socialism, the spirit of the times, mainstream media, film and television programs, etc. During the teaching process of advanced mathematics, we should have more interactive activities with students to understand the mathematics problems in students' lives, and be good at digging out the elements of "curriculum ideology" that students like, resonating with the "curriculum ideology" in students" minds, and inspiring students better to learn advanced mathematics courses well, make advanced mathematics courses truly become students' favorite courses, and let "curriculum ideology" truly integrate into advanced mathematics courses.

\section{References}

1. Yang W, Chen H, Liu S. Ideological and political exploration and practice of university mathematics courses-Taking the linear algebra teaching of Xidian University as an example. University Education 2020; (3): 77-79.

2. Wang X. Investigation on the "behavioral participation" of students in independent colleges in higher mathematics learning. Journal of Mathematics Education 2011; (20): 51-53.

3. Wang Y. Investigation and analysis of the higher mathematics learning situation of Hebei Minority preparatory students. China Electric Power Education; 2009.

4. Jin R. Thoughts on the training of logistics professionals in higher vocational education in the new era. Education Teaching Forum 2020; (8): 97-99.

5. Dong X, Nie X, Li G. Investigation and analysis of students' learning advanced mathematics—-Taking Liaodong University as an example. Higher Education Magazine 2016; (10): 38-40.

6. Huang Y. Some thoughts on the teaching of "advanced mathematics" under the ideological and political concept of the curriculum. Journal of Scientific Education-Electronic Edition (Last Ten) 2019; 000(009): 178. 